\title{
Ensaio da história do trabalho doméstico no Brasil: um trabalho invisível
}

Test of the history of domestic work in Brazil: an invisible job

\author{
Deide Fátima da Silva \\ Universidade Federal de Viçosa \\ deidefs@yahoo.com.br
}

Maria das Dores Saraiva de Loreto Professora e orientadora no Departamento de Economia Doméstica da Universidade Federal de Viçosa/MG mdora@ufv.br

Amélia Carla Sobrinho Bifano Professora e co-orientadora no Departamento de Economia Doméstica na Universidade Federal de Viçosa/MG ACSBIFANO@GMAIL.COM

Resumo O trabalho doméstico é uma atividade que tem sido foco de muitos estudos, examinando suas características e condições, manifestadas pela invisibilidade e desvalorização social. Nesse contexto, 0 presente estudo teve como objetivo desenvolver um ensaio teórico a respeito da história do trabalho doméstico no Brasil, analisando como tem sido contemplada tal atividade no meio social brasileiro, a partir de alguns estudiosos acerca do assunto. Para tanto, foi feito uso da pesquisa bibliográfica, para a explanação do campo histórico, considerando a base de dados do Portal de Periódicos CAPES, SciELO e no Google 
Acadêmico. Os resultados evidenciaram que, no Brasil Colônia, tal atividade teve seu marco histórico, expressa basicamente como trabalho escravo. No Brasil Império, entre 1822 e 1889, foi possível constatar que, mesmo após a libertação dos escravos, com a Lei Áurea, muitos continuavam servindo aos seus empregadores, por falta de oportunidades sociais. Já no Brasil República, de 1889 até os dias atuais, o avanço do capitalismo e a Revolução Industrial levaram à disputa do trabalho e desigualdade salarial entre homens e mulheres. No entanto, os dispositivos legais e os movimentos sociais passaram a reivindicar pelos direitos femininos, por intermédio do primeiro Sindicato, seguido das Leis Trabalhistas, da CF/1988 e da Organização Internacional do Trabalho (OIT), buscando atenuar as condições de precariedade vivenciadas pelas mulheres. Assim, em 2013, foi criada a PEC das Domésticas, que ampliou os seus direitos, apesar da invisibilidade do trabalho doméstico pela sociedade.

Palavras- chaves: Trabalho Doméstico; História; Direitos.

Abstract Domestic work is an activity that has been the focus of many studies, examining its characteristics and conditions, manifested by invisibility and social devaluation. In this context, the present study aimed to develop a theoretical essay on the history of domestic work in Brazil, analyzing how this activity has been contemplated in the Brazilian social environment, from some scholars on the subject. For this, use was made of the literature, for explanation of the historical field, considering the database from the Portal of CAPES periodicals, SciELO and Google Scholar. The results showed that, in colonial Brazil, this activity had its historical, expressed basically as slave labor. In Brazil Empire, between 1822 and 1889, it was found that, even after the liberation of the slaves, with the Golden Law, many still serving their employers, for lack of social opportunities. In Brazil Republic, from 1889 to the present day, the advance of capitalism and the Industrial Revolution led to the labor dispute and wage inequality between men and women. However, legal provisions and social movements began to claim for women's rights, through the first Trade Union, followed by 
Labor Laws, CF/1988 and the International Labor Organization (OIT), in order to alleviate the precarious conditions experienced by women. Thus, in 2013, was created the PEC of Domestic, which expanded their rights, despite the invisibility of domestic work by society.

Keywords: DOMESTic work; History; Rights.

\section{INTRODUÇão}

O trabalho doméstico é uma atividade que tem sido objeto de estudo de muitas pesquisas, examinando suas particularidades e, ao mesmo tempo, evidenciando a precariedade que lhe é atribuída socialmente. Evidências empíricas anteriores focalizam sua atenção em compreender a gênese dessa invisibilidade, que surge a partir da desvalorização social que é atribuída ao trabalho doméstico, que, em sua maioria, é realizado por mulheres.

Diante desse cenário, o presente estudo teve como objetivo realizar um ensaio teórico sobre a história do trabalho doméstico no Brasil, analisando como tem sido contemplada tal atividade no meio social brasileiro, a partir de alguns estudiosos a respeito dessa temática. Para tanto, foi feito uso da pesquisa bibliográfica para a explanação do campo histórico, bem como de uma investigação no CAPES, Google Acadêmico e Scielo.

Segundo Meneghetti (2011), o ensaio teórico desde a época de Montaigne assume diferentes formas e formatos, e deve ser lido por "sujeitos, com espírito livre de preconceitos, sem estarem dominados pelo formalismo da ciência"; ou seja, no ensaio os leitores não encontrarão "a disposição formal de um estudo que segue a divisão e a lógica estabelecida pelas metodologias científicas tradicionais". Sendo assim, nesse tipo de produção bibliográfica, o leitor não encontrará o objetivo geral, objetivos específicos, justificativa, fundamentação teórica, entre outros, mas será guiado por "orientações que é dada não pela busca das respostas e afirmações verdadeiras, mas pelas perguntas que orientam os sujeitos as reflexões mais profundas" (MENEGHETTI, 2011, p. 321). 
Tal autor acrescenta ainda sobre o ensaio:

Os ensaios são muito utilizados na área das ciências sociais. Grande parte dos cientistas sociais, políticos e sociólogos utilizam-se da forma ensaística para produzir reflexões sobre os acontecimentos mais relevantes da sua época. A forma ensaística consolidou vários autores conhecidos como Marx, Weber, Norbert Elias, etc. No Brasil, Raimundo Faoro, Darcy Ribeiro, Antônio Candido, são nomes importantes que se utilizaram do ensaio para refletir sobre a formação social no Brasil. Apesar das contribuições expressivas nas áreas econômicas, ciências sociais, economia etc. nenhuma área do conhecimento utilizou tanto o ensaio como a Filosofia, sobretudo os filósofos iluministas. Alguns exemplos são referências; entre eles destacam-se: Rousseau (1973) com o Ensaio sobre a origem das línguas; Locke (1997) com o Ensaio acerca do entendimento humano; Hume (1996) com sua Investigação acerca do entendimento humano. Posteriormente, outros filósofos utilizaram o recurso do ensaio para pensar e experimentar a realidade, como Bachelard (1998) e Habermas (2001), por exemplo. (MENEGHETTI, 2011, p. 321).

O filósofo francês Montaigne (2004 apud BOAVA, et al., 2012, p. 8), em seu livro Essais, foi quem elaborou essa modalidade de texto, quando discorreu sobre acontecimentos que lhe sucediam, fazendo assim reflexões acerca do assunto, como transcrito:

Contemplando o trabalho de um pintor que tinha em casa, tive vontade de ver como procedia. Escolheu primeiro o melhor lugar no centro de cada parede para pintar um tema com toda a habilidade de que era capaz. Em seguida encheu os vazios em volta com arabescos, pinturas fantasistas que só agradavam pela variedade e originalidade. O mesmo ocorre neste livro, composto unicamente de assuntos estranhos, fora do que se vê comumente, formado de pedaços juntados sem caráter 
definido, sem ordem, sem lógica e que só se adaptam por acaso uns aos outros [...]. Quanto ao segundo ponto fiz, pois, como o pintor, mas em relação à outra parte do trabalho, o melhor, êxito. Meu talento não vai tão longe, e não ouso empreender uma obra rica, polida e constituída em obediência às regras da arte.

Para os referidos autores, o ensaio "é algo inabitual. Busca-se aquilo que é incomum, o não contemplado, o novo”. Já Ricoeur (1988 apud BOAVA et al., 2012, p. 8) afirma que o ensaio "demonstra que na interpretação de um texto há uma libertação das palavras do indivíduo que escreve, quando da leitura por outrem. O indivíduo que escreve contribui com as palavras, e o leitor com a significação".

Diante do exposto, o presente trabalho buscou discorrer sobre a história do trabalho doméstico no Brasil, perfazendo o seguinte percurso:

No Brasil Colônia, procurou-se enfatizar o surgimento do trabalho doméstico; ou seja, buscaram retratar os estigmas vivenciados pela escravidão, tendo como foco as mulheres, principalmente, as negras. Naquela época, por meio de um "código de moral patrões e patroas deveriam prover proteção, alimentação, moradia, roupas aos criados e às criadas e, em contrapartida, estes deveriam oferecer obediência e fidelidade" (DAMATTA; GRAHAM, 1992 apud BERNARDINO-COSTA, 2007, p. 15). Com isso, observa-se que a atividade doméstica apresenta resquícios da escravidão até os dias atuais.

No Brasil Império, buscou-se retratar como seus contornos eram vivenciados pelos trabalhadores domésticos e, mesmo após a libertação com a Lei Áurea, muitos continuavam servindo aos seus empregadores, pois tinham com os mesmos certa aproximação e também porque não tinham o que fazer e muito menos para onde ir. Essa proximidade com a família permitia proteção às trabalhadoras, condição essa considerada por algum privilégio, por outra continuidade da relação escravocrata (BERNARDINO-COSTA, 2007, p. 229-230); mas que, inevitavelmente, expunha-as às violações de direitos, reproduzidas nesse século (SANTOS, 2010, p. 45).

Já no Brasil República, a ênfase foi de como a empregada doméstica começou a sair da invisibilidade e passou a ter direito por meio 
da fundação do primeiro Sindicato das Empregadas Domésticas, em Santos, criado por Laudelina de Campos Melo; dos direitos previstos na Consolidação das Leis Trabalhistas; da promulgação da Constituição de 1988 e vigente até os dias atuais. A preocupação da Organização Internacional do Trabalho (OIT), tratadas na Convenção do Trabalho Decente para Trabalhadoras e Trabalhador Doméstico, em 2011, discutiu a situação da empregada doméstica, culminando, no Brasil, com a criação da PEC das Domésticas, que ampliou os direitos das mesmas, estando em voga a discussão sobre como será visto os novos direitos pela classe trabalhadora beneficiada e pela sociedade.

Acrescenta que, ao discorrer sobre o Trabalho Doméstico no Brasil, procurou-se também direcionar e relembrar os acontecimentos históricos da época a fim de tornar o ensaio mais interessante e, com isso, fazer que se crie no leitor questionamentos sobre as condutas de determinados períodos.

\section{Características do trabalho doméstico no Brasil Co- LÔNIA (1500 A 1822)}

O período colonial vigorou durante os séculos XVI ao XIX, sendo caracterizado pela chegada dos primeiros portugueses ao Brasil, em 1500, bem como pela independência, em 1822. Essa época foi marcada por dois grandes ciclos econômicos, respectivamente, o ciclo do açúcar e o ciclo da mineração. O ciclo da mineração, além de ser uma fase propulsora do tráfico negreiro, tornou-se uma atividade altamente lucrativa para a metrópole portuguesa, que liberou o ingresso de escravos vindos da África no Brasil.

Acrescenta-se que o Trabalho Doméstico teve seu marco histórico no período colonial, onde a atividade doméstica era entendida como trabalho escravo, realizado por mulheres, principalmente as negras. Segundo Gomes (2016), em seu texto "a origem do trabalho doméstico no Brasil", a atividade desenvolvida pela empregada doméstica era "de mucamas, amas de leite, costureiras, aias, pajens, cozinheiros, também cuidavam dos filhos dos senhores, transmitiam recados, serviam à mesa, recebiam as visitas e etc." 
Gilberto Freyre (2003), em sua obra "Casa Grande \& Senzala", retrata a influência da cultura africana na formação do povo brasileiro, quando ele descreve o cenário do trabalho doméstico desenvolvido entre a senzala e a casa grande; ou seja, nas relações entre senhores e escravos, que eram pautadas no amor e ódio, nas condições de trabalho desenvolvidas no acordo pessoal, no entendimento, na colaboração, exploração, bem como por meio da convivência diária, que obscurecia a separação entre atribuições e gentilezas, direitos e deveres e, principalmente, empregados e patrões.

No período escravocrata, as trabalhadoras domésticas moravam na senzala, mas passavam grande parte do dia na Casa Grande. Com o redimensionamento das casas na zona urbana, esses dois lugares fundiram-se e foi criado um novo cômodo nas casas: o quarto da empregada. Assim, o quarto da empregada mantém a relação com o trabalho escravo, pois conserva a presteza servil do século XIX, impede o controle da trabalhadora sobre sua jornada de trabalho e tempo de descanso, além de afastar essas mulheres do convívio com suas próprias famílias (SANTOS, 2010).

O quarto de empregada foi criado como uma forma de controlar a jornada de trabalho da empregada doméstica, levando-a ao isolamento e ao desconforto, uma vez que eram espaços sem ventilação e insalubres, além de ser considerado como uma relação de trabalho, uma vez que os "laços e dependências afetivas recíprocas entre a trabalhadora e a família são diluídos na distância física, redimensionando-se para o reconhecimento do valor profissional da trabalhadora. Depois, porque ao morar na casa dos empregadores a trabalhadora fica na dependência dos horários dos donos da casa" (SANTOS, 2010, p. 35).

Sobre as senzalas, além de insalubres, eram consideradas como cubículos com divisória interna, mas destituídos dos elementos que permitiam a intimidade; ou seja, coberta de palha ou telhas, erguidas com tijolos, madeira ou pedras. Algumas dispunham de divisórias internas, outras abrigavam apenas mulheres, mas estavam sempre presentes quando o número de escravos era relevante (ALGRANTI, 1997, p. 95).

A empregada doméstica ficava tão restrita ao seu local de trabalho, que desenvolvia com a família empregadora laços de afetividade, sendo 
que o mesmo não acontecia com seus próprios familiares. Além disso, as trabalhadoras passavam por privações quanto à utilização de banheiros, talheres e alimentos, inclusive quanto ao local que lhes era designado e os utensílios permitidos para uso, também quanto a sua permanência nos cômodos da casa, enquanto o empregador estivesse presente (SANTOS, 2010).

Conforme Graham (1992), citado por Bernardino-Costa (2007, p. 15), naquela época havia um código de moral, onde os patrões deveriam promover a proteção, alimentação, moradia, roupas de seus criados; em contrapartida, os mesmos deviam obediência e fidelidade. Acrescenta-se ainda que os espaços casa e rua eram definidos da seguinte forma: a casa como "um domínio seguro e estável" e a rua como "lugar suspeito e imprevisível", afirmando:

\footnotetext{
"Embora essas categorias fossem reconhecidas" por senhores e criadas, os significados convencionais podiam ser revertidos ou se tornar ambíguos: para os criados, a casa podia ser um local de injustiça, punição ou trabalho excessivo, enquanto a rua podia ser procurada como um local de maior liberdade. Já os senhores enfrentavam os riscos inescapáveis de trazer criados desordeiros para os espaços (GRAHAM, 1992, apud BERNARDINO-COSTA, 2007, p. 15).
}

Com relação aos laços de afetividade desenvolvidos entre a empregada doméstica e a família empregadora, cabe o seguinte questionamento: será que havia afinidade entre ambas as partes? Ou a empregada doméstica, por estar restrita ao seu local de trabalho, se acomodava à forma como era tratada? Será que considerava normal tudo o que passava? Será que temia os maus-tratos, violência e perseguições, caso fugisse?

Remetendo-se aos informativos e jornais da época, foi possível constatar que os escravos, amas de leite, principalmente as mulheres e homens negros, eram considerados como coisa, objeto; ou seja, eram equiparados a mercadorias rentáveis e de raça inferior de propriedade dos senhores e fazendeiros, podendo os mesmos se desfazer deles, 
vendendo-os ou perseguindo-os em caso de fuga, como reproduzido nos anúncios apresentados nas Figuras 1 e 2.

\section{Figura 1 - Anúncio sobre fuga da Escrava}

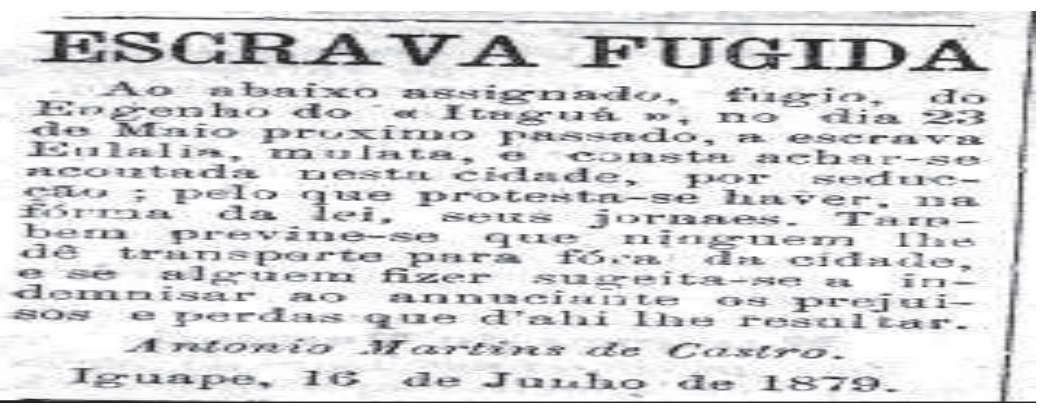

Fonte: Disponível em: $<$ http://robertofortes.fotoblog.uol.com.br/photo20050214175708.html $>$ Acessado em 14/02/2016

Figura 2 - Anúncio sobre venda de Ama de Leite

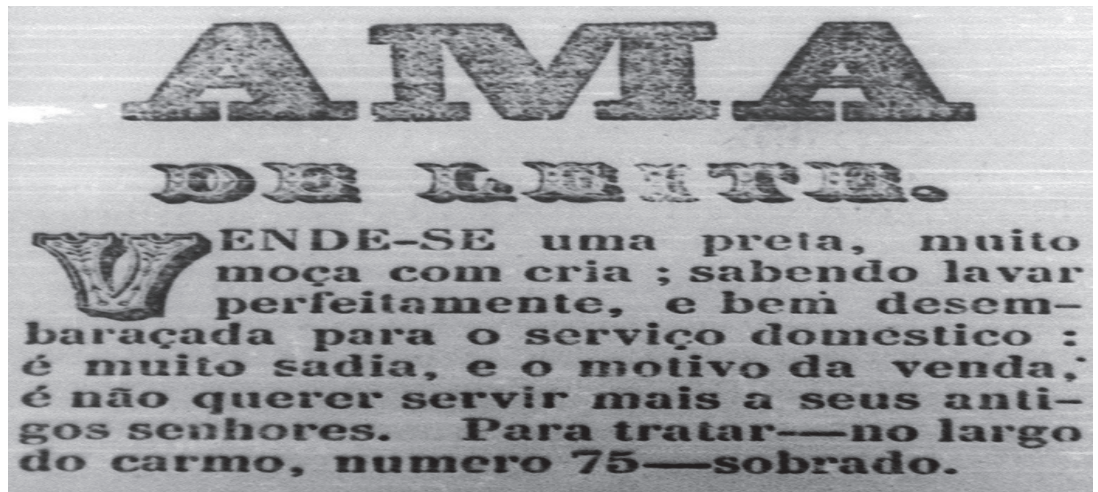

Fonte: Disponível em: http://www.saopauloantiga.com.br/anuncios-de-escravos/ Acessado em 14/02/2016

Questiona-se, a respeito dos escravos que não fugiam ou se rebelavam contra os patrões, quais seriam os sentimentos, que eles desenvolviam pela família empregadora, que os faziam aceitar os tratamentos que tinham. 
Destaca-se que o trabalho feminino, na época colonial, sofria também a influência da cultura portuguesa, uma vez que a mulher era responsável pelo papel de provedora de alimentos da família, organização doméstica, e pelo trabalho manual, enquanto que as escravas ficavam responsáveis pela limpeza e preparo da casa. Era característico que os moralistas e as pessoas preocupadas com a educação feminina recomendassem que as mulheres se dedicassem ao trabalho manual, como forma de evitar ociosidade, maus pensamentos e ações, que não eram condizentes com a realidade vivida (ALGRANTI, 1997).

Nesse período, o Brasil vivenciava os efeitos do Pacto Colonial imposto pela Coroa portuguesa, além da compra de produtos manufaturados vindos de Portugal, quando eclodia na Europa a revolução Industrial, que tinha como particularidade a substituição do trabalho artesanal pelo assalariado e uso de máquinas.

É importante salientar que, no Brasil, a revolução industrial somente teve início na segunda metade do século XIX, com a crise do café em São Paulo, que levou os cafeicultores a investir no setor industrial, considerado o modelo de substituição de importações.

\section{O TRABALHO DOMÉSTICO NO BRASIL IMPÉRIO (1822 A 1889)}

O Brasil Império vigorou desde a Independência do Brasil, em 7 de setembro de 1822, à Proclamação da República, em 15 de novembro de 1889, perpassando por dois governos monárquicos de D. Pedro I e D. Pedro II. Em 1823, houve a reunião da Assembleia Geral Constituinte, com o objetivo de criar a primeira Constituição Brasileira, que foi outorgada por D. Pedro I, em 1824.

Elucida-se que, em 1823, quando José Bonifácio de Andrade e Silva apresentou suas ideias de repúdio à escravidão, em nome dos direitos individuais e do progresso do império, as mesmas nem foram debatidas, uma vez que a Assembleia foi destituída por D. Pedro I. A Carta Imperial, outorgada por D. Pedro I, reproduzia literalmente as disposições da Declaração dos Direitos do Homem e do Cidadão de 1789, que versava sobre o direito inalienável à liberdade; ignorando, com isso, os 
cativos e mantendo escravizada quase a metade da população brasileira (SOARES, 2010).

Acrescenta-se que, nessa época, os negros africanos eram transportados nos porões dos navios negreiros e sofriam com a péssima condição e com o transporte desumano, além de serem vendidos no Brasil por fazendeiros e senhores de engenho como mercadoria, sendo tratados de forma cruel e violenta. Entretanto, a escravidão permaneceu por quase trezentos anos, pois era aceita e considerada normal, embora houvesse quem repudiasse tal conduta. Reconhece-se que o fator econômico seja o fator determinante para a permanência da escravidão, porque todo o trabalho desenvolvido nas minas e nas fazendas era realizado por escravos.

Com relação ao período escravocrata, um ponto importante foi o papel do Estado imperial na manutenção da escravidão, uma vez que cabia ao mesmo a tarefa de vigilância das senzalas, combate a fugas, além da "legalização do sistema escravista mediante a instauração de uma ordem jurídica que, defensora da propriedade privada, não hesitava em definir os negros escravizados como objetos da propriedade dos escravistas, portanto, protegidos pela lei”, como propõe Aquino, citado por Soares (2010, p. 436).

Na segunda metade do século XIX, começou a surgir o movimento abolicionista, sendo que, em 1850, foi extinto o tráfico de escravos no Brasil e, em 28 de setembro de 1871, foi promulgada a Lei do Ventre-Livre, onde tornava livres os filhos de escravos que nascessem após essa lei. Em 1885, foi promulgada a Lei Saraiva - Cotegipe, também conhecida como Lei dos Sexagenários, que beneficiava os negros com mais de 65 anos de idade.

Mas, foi somente em 13 de maio de 1888, por meio da Lei Áurea, que a princesa Isabel, filha de D. Pedro II, aboliu a escravidão do país. Após a abolição da escravidão, algumas escravas permaneceram nas casas de seus ex-proprietários, pois não viam muitas alternativas de trabalho e sobrevivência, questionando-se se essa situação não seria uma forma de se manter a escravidão.

Assim, as negras que permaneceram nas casas de seus ex-proprietários, exercendo as atividades domésticas, acabavam mantendo certo 
"status", comparativamente ao restante da população negra, uma vez que essa proximidade com a família permitia certa proteção às trabalhadoras. Essa condição era considerada, por um lado, como privilégio, mas, por outro, como uma continuidade da relação escravocrata (BERNARDINO-COSTA, 2007, p. 229-230), que, inevitavelmente, as expunha às violações de direitos, reproduzidas nesse século (SANTOS, 2010, p. 45).

O autor ressalta que essa situação era derivada do fato de que os ex-escravos, que lidavam com os afazeres domésticos, embora presenteados com a liberdade advinda da lei Áurea, permaneciam com seus antigos senhores sem receber salários, apenas em troca de abrigo e comida, já que muitos não tinham para onde se refugiar nem o que fazer. Como se diz: adianta dar liberdade aos escravos se não oferece ao mesmo emprego digno, com salários e meios para a sua sobrevivência?

No século XIX, esse contexto histórico mudou as relações sociais e trabalhistas, pois a situação de senhora e escrava passou para patroa e empregada, principalmente, quando a mulher das classes dominantes começou a se preocupar com as questões domésticas, tendo em vista a propagação do medo social de contágio da família e da casa, considerando que as empregadas domésticas, que eram negras, eram vistas como fonte de contaminação, desleixadas, sujas, incompetentes. Essa representação relevou a que as mulheres brancas retornassem às atividades da casa ou, caso mantivessem as escravas, utilizassem de coação sobre suas atividades com a ameaça de desemprego (SANTOS, 2010).

Nesse período, também, os valores burgueses conflitavam com o patriarcalismo escravista em relação às atividades domésticas, que, apesar de "marginal ao mercado formal, o trabalho doméstico é valorizado e esquadrinhado nos manuais de economia doméstica em contraposição a um comportamento feminino dentro da casa colonial interpretado como ocioso" (CARVALHO, 2008, p. 241). Esses manuais de economia doméstica visavam estabelecer regras de etiquetas e de como a mulher poderia ser uma boa dona de casa, esposa e cuidar bem dos filhos a fim de garantir a prosperidade da família. 
Também é importante destacar que, em 1886, foi criado o primeiro dispositivo legal a regular as diversas normas específicas para os trabalhadores domésticos no Brasil, ao qual se deu o nome de Código de Posturas do Município de São Paulo, no qual foram estabelecidas as primeiras regras para as atividades das "ama de leite" e dos "criados", de acordo com Gomes (2014), citado por Bentivoglio (2014).

$\mathrm{O}$ referido dispositivo definiu que:

O criado de servir, como toda pessoa de condição livre, que mediante salário convencionado, tiver ou que quiser ter ocupação de moço de hotel, hospedaria ou casa de pasto, cozinheiro, copeiro, cocheiro, hortelão, ama de leite, ama-seca, engomadeira ou costureira e, em geral, a de qualquer serviço doméstico. (Artigo 263, Código de Posturas do Município de São Paulo) (MARTINS, 2013, apud BENTIVOGLIO, 2014, p. 221).

Ressalta-se que o Código de Postura do Município de São Paulo, instituído no período escravocrata, não tinha como objetivo resguardar as empregadas domésticas contra os abusos de seus patrões, mas sim de estabelecer mecanismos que garantissem o controle dessas trabalhadoras por seus empregadores (MAZIERO, 2010, p. 19).

Ao ser estabelecida a obrigatoriedade de registro de todas as empregadas dessa categoria perante a Secretaria de Polícia, foi expedida uma caderneta para efeito de identificação, além de: "prévia a imposição de dispensa por justa causa da empregada, que ficasse impedida de trabalhar por motivo de doença, ou que saísse de casa a passeio ou a negócio, sem licença do patrão, mormente à noite", como pontua Martins (2007), apud Maziero (2010, p. 19).

Com a proclamação da República, no dia 15 de novembro de 1889 , encerra-se a monarquia e se inicia a República, que vigora até os dias atuais, sendo marcada por vários acontecimentos, que refletem direta e indiretamente nos direitos dos trabalhadores domésticos. 


\section{Aspectos laborais das domésticas no Brasil República (1889 aTÉ OS DiAS ATUAIS)}

Segundo Figueiredo (2011, p. 21-22), o Brasil Colônia e o Brasil Imperial foram marcados por uma "soberania política, do qual era inútil qualquer resistência das outras classes sociais". E, com isso, houve fatores como "centralização política e administrativa, a abolição da escravatura", entre outros, que impulsionaram a queda do império.

A Primeira República ou República Velha, como é conhecida, vai de 15 de novembro de 1889 até a Revolução de 1930, dividindo-se em dois períodos, sendo, por um lado, o primeiro chamado República da Espada, que vai de 1889 até a posse do primeiro presidente civil, Prudente de Moraes. Essa época é caracterizada por um viés mais centralizador do poder, pois havia o temor do regresso da monarquia. Por outro lado, o segundo período, chamado República Oligárquica, que vai de 1894 até a Revolução de 1930, era marcado pelo poder das elites regionais de São Paulo e Minas Gerais e pela política do café com leite, em função da importância econômica da produção de café paulista, e do leite mineiro para a economia do Brasil.

O projeto da República foi baseado nas "constituições norte- americana e argentina, com algumas ideias da Suíça” e, segundo Octaciano Nogueira, citado por Figueiredo (2011, p. 23):

...o desejo de apressar a votação da Constituição, para que o país entrasse o quanto antes no regime legal, levou os constituintes a só discutirem os pontos principais do projeto- a organização federativa, a discriminação de rendas, a unidade do Direito, a dualidade de magistratura, o sistema de eleição presidencial, a liberdade religiosa, a organização dos estados e alguns outros, tendo havido não poucos requerimentos de rolha (encerramento da discussão), para o encerramento do debate.

Figueiredo (2011) acrescenta que, após o período de transição entre a Monarquia e a República, levou-se um tempo para que fosse 
criada a primeira Constituição, promulgada em1891 e perdurando até 1930, constituição esta que expressa valores respaldados na filosofia política republicano-positiva, bem como em princípios dos clássicos liberalismos individualistas.

A Primeira República ficou conhecida como "República dos Coronéis" e consequentes movimentos revolucionários. Mas, por sua vez, esse período foi marcado pela inauguração do sistema presidencialista de governo, pelo sistema de voto direto e universal, além de considerar implicitamente que as mulheres não poderiam votar, uma vez que não fez remissão às mesmas na Constituição (FIGUEIREDO, 2011).

Acrescenta-se que, enquanto isso, no mundo afora, eclodia a Primeira Guerra Mundial, em 1914, a Crise de 29 e a sucessão; ou seja, no final do século XVIII e início do XIX, surgiu o Romantismo, que fazia prevalecer os sentimentos sobre a frieza da razão e a imaginação sobre a análise racional, consagrando a espontaneidade. Ainda sob as luzes do século XIX, inicia-se a Revolução Industrial e se instaura o capitalismo, promovendo os direitos individuais, incluindo as mulheres, bem como um novo modelo de relacionamento entre homens e mulheres (ZAMBERLAM, 2001, p. 49).

A revolução industrial desenvolveu-se na Europa, no século XVIII e XIX, sendo considerada um conjunto de mudanças com o intuito de substituir o trabalho artesanal pelo uso de máquinas e assalariado. Mas, foi a Inglaterra a precursora de seu desenvolvimento, pelo fato de possuir uma rica burguesia e ter uma importante zona de livre comércio da Europa.

Tal revolução trouxe a disputa do trabalho entre o homem e a mulher. A mulher possuía mão de obra mais barata que o homem; porém, produzia menos em virtude de suas ocupações domésticas. As mulheres sujeitavam-se a jornadas de 14 a 16 horas por dia, a condições prejudiciais à saúde e a muitos outros abusos, para não perderem o emprego. Essas revoluções, além de separar o mundo do trabalho do mundo familiar, instituindo-se a dimensão privada da família em contraposição ao mundo público, provocaram mudanças significativas relacionadas ao impacto do desenvolvimento tecnológico, como discutido por Costa (2000), referendado por Zamberlam (2001, p. 50): 
A revolução Industrial e o capitalismo, ao aceitarem a mulher no mercado de trabalho, paradoxalmente, contribuíram para que ela deixasse de ser propriedade privada familiar e passasse da posição exclusiva de reprodutora para se tornar, também, produtora, dando um importante passo para sua libertação.

Essas mudanças nas condições do trabalho feminino podem ser criticadas, uma vez que o desaparecimento da sociedade artesanal, levando as mulheres a buscarem trabalho nas manufaturas, ocorria em um ambiente precarizado, na medida em que aceitavam salários inferiores aos dos homens e em locais insalubres, para serem acolhidas. A exploração das operárias, a miséria e a prostituição daí decorrentes, lentamente trouxeram consciência dos problemas resultantes da inserção da mulher na sociedade industrial. Essas modificações acentuaram-se ainda mais no século XX, consolidando-se após a Primeira Guerra Mundial, quando as mulheres entraram no mercado de trabalho e conquistaram vários direitos.

A inserção da mulher no mercado de trabalho nas fábricas, como operárias, na França e Inglaterra, se deu devido ao fato da mão de obra ser considerada desvalorizada e altamente lucrativa para os empregadores, além de ser uma forma das mesmas complementarem a renda dos maridos.

A mulher desde a sociedade patriarcal sempre foi submissa ao homem e associada à atividade reprodutiva, de cuidados da casa e dos filhos. Mas, foi nesse período, com a entrada da mulher no mercado de trabalho industrial, que surgiram os movimentos feministas, questionando os estereótipos sobre o papel feminino e abrindo novas oportunidades para as mesmas frente ao mercado de trabalho, educação e outros setores da sociedade.

No final da década de 1960 e início da de 1970, pesquisas que se tornaram clássicas na literatura sobre o trabalho da mulher, como a de Saffioti (1969) e a de Blay (1978), abordaram essa questão, rapidamente tornando-se leitura obrigatória nas universidades. O Ano Internacional da Mulher, em 1975, constituiu um marco, a partir do qual a produ- 
ção sobre o tema ganhou maior destaque. A emergência do feminismo, como movimento social, criou as condições necessárias para a legitimação da condição feminina, como objeto de estudo, além de analisar a condição da mulher a partir do seu papel na reprodução da força de trabalho, enfocando o trabalho doméstico (BRUSCHINI, 2006, p. 2).

Os movimentos feministas buscaram discutir não somente a invisibilidade e a inferioridade feminina, mas também a desqualificação do trabalho doméstico, a fim de reinterpretar seu conceito, bem como o do trabalho produtivo e improdutivo. As críticas formuladas pelas feministas acadêmicas a essa invisibilidade do trabalho feminino ajudaram a ampliar a discussão sobre as formas de valorizar o papel das mulheres nas duas instâncias sociais: a de reprodução e a de produção (MELO, 2009, p. 138-139).

De acordo com Bruschini (2006), embora o trabalho doméstico estivesse sido ignorado nos estudos sobre o trabalho, no contexto da sociedade capitalista, este ainda era importante na configuração da divisão sexual do trabalho, pois demonstrava o estreito vínculo do trabalho remunerado com o não remunerado. Essa nova perspectiva de análise, articulando a esfera da produção econômica e da reprodução, permitiu observar as consequências das obrigações domésticas na vida das mulheres, limitando seu desenvolvimento profissional. Com carreiras descontínuas, salários mais baixos e empregos de menor qualidade, as mulheres, muitas vezes, acabam por priorizar seu investimento pessoal na esfera privada (BRUSCHINI, 2006, p. 8).

Fazendo um parêntese com relação à questão da invisibilidade do trabalho doméstico, tanto remunerado quanto não remunerado, ressalta-se o valor que deveria ser dado ao trabalho caseiro, até mesmo pelas próprias mulheres, ao não considerá-lo como atividade econômica.

Para explicar esse parêntese, compartilha-se do entendimento de Bruschini (2006), em seu artigo "Trabalho doméstico": inatividade econômica ou trabalho não remunerado? A autora destaca que o trabalho doméstico realizado dentro de casa, apesar de não ser remunerado, não pode ser considerado como inatividade econômica, uma vez que se emprega tempo em sua realização. Com isso, ela tenta dar uma visibilidade 
ao trabalho doméstico, tendo como base o estudo sobre orçamento-tempo desenvolvido em outros países, após a Segunda Guerra Mundial, por exemplo, Grã-Bretanha, União Soviética, Estados Unidos, França e Alemanha. Na década de 1970, tal metodologia foi incorporada ao Brasil, com o intuito de tornar visível e valorizar a atividade doméstica, assim como outra forma de atividade sem remuneração, desempenhada pelas mulheres (BRUSCHINI, 2006, p. 5-6).

$\mathrm{Na}$ visão de Sanches (2009), por nós compartilhada, o trabalho doméstico, seja ele remunerado ou não, entendido como natural, apenas reproduz o cuidado feminino, e, portanto, não foi por muito tempo qualificado como trabalho, porque não gera lucro e não visa o mercado, sendo considerado invisível, embora seja uma das mais antigas e significativas ocupações das mulheres no mundo. O cuidado com os membros familiares e com o domicílio, não importa quem faça, é indispensável para o sistema familiar e para o funcionamento geral da economia. Portanto, é essencial "desnaturalizá-lo para fazer valer"; ou seja, é importante trazer o emprego doméstico para fora de sua invisibilidade e desvalorização, colocando-o como uma categoria profissional, com requisitos próprios, provendo, assim, políticas e ações sociais com o intuito de posicionar a empregada doméstica em "condições de exercício da cidadania plena e de superação a pobreza e as más condições de vida e trabalho" (SANCHES, 2009, p. 885-887).

Observa-se que o trabalho doméstico é uma atividade que foi negligenciada e sofreu uma latente invisibilidade jurídica, inclusive no Brasil República; ou seja, foi somente em 1916, por meio da Lei 3.071, do Código Civil de 1916, que começaram a surgir normas que poderiam ser direcionadas às empregadas domésticas, quando "disciplinou a relação dos contratos trabalhistas relacionados à locação de serviços dos empregados, inclusive dos domésticos, sendo este aplicável dentro das possibilidades". Posteriormente, surgiu o "Decreto n' 16.107, de 30 de julho de 1923, que também aprovou o regulamento de locação de serviços domésticos, onde traz todos os dispositivos necessários para atender as necessidades e interesses desses trabalhadores" (CHAGAS, 2013, p. 5). 
No período entre1930 e 1945, conhecido como a Era Vargas, que compreende a segunda e terceira república, podem ser identificadas três fases: o período do Governo Provisório (1930 a 1934), o período da Constituição de 1934 e o período do Estado Novo (1937 a 1945). Com relação ao trabalho doméstico, foi justamente na década de 1930 que as primeiras organizações profissionais colocaram pressão no Estado, frente à necessidade de regulamentar essa atividade, marcada desde o pós-abolição sem direitos trabalhistas ou qualquer tipo de regulamentação.

Assim, em 24 de fevereiro de 1932, Getúlio Vargas criou o novo Código Eleitoral e o anteprojeto da Constituição, sendo que, no novo código Eleitoral, foi estabelecido o voto secreto e o voto feminino, como também o voto classista; isto é, os sindicatos, tanto patronais quanto de trabalhadores, elegeram deputados que teriam os mesmos direitos dos demais parlamentares.

Em 16 de julho de 1934, foi promulgada a Constituição de 1934, "que garantiu o direito à sindicalização, mas este não estendido ao trabalho doméstico (SANTOS, 2010 p. 47)". É importante ressaltar que, em 1932, sobre forte movimentação das trabalhadoras domésticas e com o surgimento de associações, que tinham como objetivo defender os direitos trabalhistas das relações entre empregadas e patrões, surgiu a Associação dos Empregados Domésticos de Santos, fundada por Laudelina de Campos Melo e criada para ser um Sindicato (PEREIRA, 2012, p. 4).

Em uma entrevista, Laudelina explica sobre sua tentativa de falar com Getúlio Vargas, na expectativa de que houvesse enquadramento da classe de empregadas domésticas na legislação trabalhista, como aduz:

O Getúlio já tinha instituído as leis sindicais e ia haver o primeiro congresso (de trabalhadores em 1936)... As empregadas domésticas foram destituídas das leis trabalhistas, nós estávamos criando um movimento para ver se conseguia o registro do Sindicato... Eu fiquei no Rio uns três ou quatro dias, no terceiro dia eu consegui com o secretário do ministro. Fui falar com o Ministro, mas não adiantou nada porque não havia possibilidade 
de enquadramento da classe das empregadas domésticas (Laudelina de Campos Melo, entrevista a Elisabete Pinto) (PEREIRA, 2012, p. 4).

O Brasil passou ainda pelos governos de Eurico Gaspar Dutra (1946-1951), Getúlio Vargas (1951-1954), Juscelino Kubitschek (19561961), Jânio Quadros (1961), João Goulart (1961-1964). Após o Golpe de 64, o regime adotado no país foi o Regime Militar, e teve como presidente Marechal Castelo Branco (1964-1967), Marechal Costa e Silva (1967-1969), Marechal Médici (1969-1974), General Ernesto Geisel (1974-1949), João Figueiredo (1979-1985).

Por sua vez, a Nova República teve os seguintes presidentes: José Sarney (1985-1990), Fernando Collor (1990-1992), Itamar Franco (1992-1993), Fernando Henrique Cardoso (1995-2003), Luiz Inácio Lula da Silva (2003-2011), Dilma Rousseff (2011 até 2016).

Os governos descritos foram marcados por vários acontecimentos entre eles: Revolução Constitucional, Golpe Militar, Suicídio, Redemocratização, "50 anos em 5", Ato Institucional (AI-5), Plano Cruzado, Impeachment, Plano Real, Corrupções, Escândalo da Petrobrás, Passeata e Manifestação do povo contra o governo, entre outros. Enquanto isso, no mundo, aconteciam muitos outros episódios, com reflexos direta ou indiretamente no Brasil, como a Guerra Fria, ataques terroristas, entre outros.

Nos governos já citados, ressalta-se a invisibilidade do trabalho doméstico, que lhe é atribuído a partir da desvalorização social, principalmente porque é um trabalho realizado em grande maioria pelas mulheres. Nesse período, houve diversas leis, na tentativa de dar algum respaldo jurídico às empregadas domésticas.

Em 11 de dezembro de 1972, a partir da aprovação da Lei 5.859, os empregados domésticos passaram a ter alguns tipos de prerrogativas, deixando de ser totalmente desprotegidos e adquirindo, assim, um pouco de cidadania, principalmente, o acesso aos seguintes direitos: benefícios e serviços da Previdência Social, férias anuais com o adicional de $1 / 3$ a mais que o salário normal e carteira de trabalho. 
Em 5 de outubro de 1988, com a promulgação da Constituição de 1988, em vigor até os dias atuais, conhecida como Constituição Cidadã, buscou-se garantir os direitos sociais, econômicos, políticos e culturais. Nela está previsto também outros direitos aos empregados domésticos, como: salário mínimo, fixado em lei, nacionalmente unificado, capaz de atender às suas necessidades vitais básicas e de sua família, como moradia, alimentação, educação, saúde, lazer, vestuário, higiene, transporte e Previdência Social, com reajustes periódicos, que lhes preservem o poder aquisitivo, sendo vedada sua vinculação para quaisquer fins; entre outros (CONSTITUIÇÃO, 1988).

Em síntese, o que se observou em relação aos direitos da empregada doméstica foi que, mesmo com a criação da Associação dos empregados domésticos de Santos, em 1932, somente com a lei 5.859/72 e com a Constituição de 1988 é que as empregadas domésticas passaram a ter algum tipo de prerrogativa; ou seja, deixando de ser tão desprotegidas e adquirindo um mínimo de cidadania, por exemplo, o da carteira de trabalho assinada. Mas, mesmo com o direito à carteira assinada, ainda sofre discriminação de sua própria categoria, como elucidado:

A recusa de algumas trabalhadoras em permitir a as-
sinatura da CTPS, de forma que não fiquem registros
de suas atividades como doméstica porque sabem que
serão prejudicadas pelo preconceito quando tentarem
outro emprego: Se a gente vir a nossa história, a gente
vem dos escravos. Então, o preconceito é tão forte que
isso ficou muito na trabalhadora doméstica. E o que
mais incomoda na luta é esse preconceito. Agora, esse
preconceito foi imposto pela sociedade. A trabalhadora
doméstica já é vítima disso (Lenira de Carvalho. En-
trevista ao SOS Corpo, 2009) (SANTOS, 2010, p. 31).

Ocorre que, nas décadas de 1960 a 1990, houve relatos de empregadas domésticas sobre as discriminações que sofriam no local de trabalho em decorrência de sua atividade, por exemplo, a identificação de elevador ou entrada de serviço e a constante identificação na portaria, por determinação do empregador ou do condomínio, como transcrito. 
Teve um belo dia que a gente mudou. Não estava com muito tempo, quando eu desço, os meninos da portaria falam assim: "Ah, dona Maria José, a senhora não vai poder passar por aqui”. Aí perguntei: "Por quê?". Disseram que tinha proibido a gente de passar e entrar pelo elevador social. "Só pelo elevador de serviço agora". [...] Ele disse [que] se eu passasse pela a porta, se eu entrasse no elevador social, meu patrão iria ter que pagar uma multa. Eu perguntei: "por quê?”. Ele disse que a ordem agora era essa. Aí, já tinha percebido que as meninas [outras trabalhadoras] davam a volta pra poder entrar (Entrevista: Maria José Silva) (SANTOS, 2010, p. 32).

Destaca-se também que, após a criação da primeira associação de trabalhadores domésticos, liderada por D. Laudelina, surgiram vários sindicatos em todo o país, culminando na criação da Federação Nacional das Trabalhadoras Domésticas - FENATRAD, em 1997. Porém, foi, em 1980, com a ascensão do movimento negro no Brasil, que entrou na agenda política a questão racial, sendo que foi o movimento de mulheres negras que destacou a importância do trabalho doméstico.

Ressalta-se que, desde o ano de 1940, que a OIT desenvolveu um interesse sobre o tema trabalho doméstico; surgindo, assim, as primeiras resoluções focando a questão dentro da Organização. Acrescenta-se ainda que, no sentido de promover a proteção mais efetiva aos direitos das/os trabalhadoras/es domésticas/os, a OIT realizou um processo de discussão a respeito do tema nas 99a (2010) e 100a . (2011) Conferência Internacional do Trabalho (CIT), que culminou na Convenção sobre o Trabalho Decente para as Trabalhadoras e Trabalhadores Domésticos, pela resolução nº 189 (2011), acompanhada da Recomendação nº 201. Entre as recomendações, elucida-se o fato que seus membros deveriam "fomentar o desenvolvimento contínuo de competência e qualificação dos trabalhadores domésticos, inclusive, se for o caso, a alfabetização de forma a melhorar suas possibilidades de desenvolvimento profissional" (OIT, 2011, p. 9-10).

A Organização Internacional do Trabalho (OIT, 2011) foi fundada, em 1919, com o objetivo de formular, adotar e supervisionar a aplica- 
ção das normas internacionais do trabalho por meio de suas convenções e recomendações, que se caracterizam como tratados internacionais, construídos através de um consenso tripartite sobre uma visão mínima de direitos para garantir um trabalho decente para homens e mulheres com relação ao tema do trabalho doméstico.

Com relação ao trabalho doméstico, a OIT, nos anos de 1948 e 1965, adotou resoluções específicas e medidas normativas relativas às condições de trabalho dessa classe de trabalhadores, assim como o lançamento do primeiro estudo sobre a atividade doméstica, no ano de 1970. Embora os empregados domésticos continuem sendo vítimas dos direitos humanos e dos direitos fundamentais no trabalho, por exemplo, a discriminação, a OIT, tendo isso em mente, retomou em sua Agenda do Trabalho Decente a discussão a respeito do trabalho doméstico, com o intuito de valorizá-lo e respeitar os direitos relacionados a esse tipo de atividade (OIT, 2011).

A referida organização considera o trabalho doméstico como um tema que apresenta grandes desafios do ponto de vista da ação pública e da organização de atores sociais, em função da sua complexidade e características peculiares, com respeito ao seu papel na estruturação do mercado de trabalho, assim como o envolvimento do mesmo com os aspectos fundamentais da organização social e das desigualdades de gênero e raça, da divisão sexual do trabalho e da desvalorização do trabalho reprodutivo.

Segundo a Organização Internacional do Trabalho, o trabalho doméstico é definido:

Como trabalho realizado por uma pessoa, no âmbito de um domicílio que não seja o de sua unidade familiar, e pelo qual se recebe uma remuneração, o trabalho doméstico compreende atividades ligadas aos cuidados como serviços de limpeza, arrumação, cozinha e cuidado de vestuário, além do cuidado das crianças, idosos, pessoas com deficiência e animais, entre outras atividades (OIT, 2011, p. 9). 
No caso do Brasil, essas mudanças propostas pela OIT ocorreram por meio de proposta de emenda à Constituição, que é a Emenda Constitucional $n^{\circ} .72$, de 2 de abril de 2013, que culminou na Lei Complementar $\mathrm{n}^{\circ} .150$, também conhecida como "PEC das Domésticas". A sigla PEC significa Proposta de Emenda à Constituição de 1988, que tem como objetivo alterar o parágrafo único do artigo $7^{\circ}$. da Constituição de 1988, estabelecendo assim uma igualdade de direitos trabalhistas entre os trabalhadores domésticos e os demais trabalhadores urbanos e rurais.

Com a promulgação da PEC, em 2013, entraram em vigor os seguintes direitos: recebimento de um salário mínimo ao mês ou piso regional para o Estado, que possuem; Pagamento garantido por lei; Jornada de trabalho de 8 horas diárias e 44 horas semanais; Hora extra; Direito a trabalhar em local onde sejam observadas todas as normas de higiene, saúde e segurança; Empregador tem que respeitar regras e acordos de convenções coletivas; Proibição de diferenças de salários, de exercício de funções e de critério de admissão por motivos de sexo, idade, cor ou estado civil; Proibição de discriminação em relação ao portador de deficiência (AVELINO, 2015, p. 8-9).

Conforme o referido autor, em 2015, as empregadas domésticas passaram a ter os seguintes direitos: Adicional noturno; Adicional de viagem; Controle obrigatório de ponto do empregado; Utilização do banco de horas; Redução da alíquota do INSS do empregador de 12\% para 8\%; FGTS; Seguro Acidente de Trabalho; Antecipação da Multa de 40\% do FGTS; Seguro Desemprego; Salário Família.

Com relação às horas trabalhadas, tal assunto pode gerar polêmicas, tendo em vista que muitas das empregadas domésticas dormiam no serviço, extrapolando assim as horas laboradas, pois tinham seu descanso interrompido pelo empregador, quando era necessária a execução de algum serviço.

Agora com a nova lei, "observe-se que, nesses períodos de descansos, se interrompido para executar algum serviço, será devido o adicional de hora extraordinária. Além disso, intervalos concedidos pelo empregador, não previstos em lei, são considerados tempo à disposição. Por isso, devem ser remunerados como serviço extraordinário" (MASCARENHAS, 2013, p. 41). 
Existem outros direitos concedidos à classe de trabalhadoras domésticas, que devido à sua importância, por si, não merecem ter comentários, mas que configuram a busca pela equiparação às demais classes de trabalhadores, o que tem sido o resultado de lutas de "movimentos feministas, raciais, e do movimento de trabalhadoras domésticas, liderado pela Federação Nacional de Trabalhadoras Domésticas" (ANDRADE, 2014, p. 31).

Com a ampliação dos direitos trabalhistas à empregada doméstica, direito esses merecidos; mas, como enfatiza Avelino (2011), tais direitos têm que ao mesmo tempo respeitar e reconhecer que:

O empregador doméstico, como gerador de trabalho e renda, e que o mesmo, e uma pessoa física sem fins lucrativos com o seu empregado doméstico, e ao mesmo tempo, que a maioria dos empregadores domésticos e da classe média, e que sua capacidade econômica e renda per capita ainda não é de primeiro mundo (AVELINO, 2011, p. 13).

Mascarenhas (2013) faz uma comparação da situação das empregadas domésticas em países desenvolvidos, como Estados Unidos, Inglaterra e França, alegando que nesses países, embora tal classe ainda não tenha conseguido igualar-se aos demais trabalhadores, a situação financeira dessas pessoas é notadamente bem melhor que no Brasil. Sendo assim, ter uma doméstica lá é considerado luxo e que só uma parte da população pode desfrutar desses serviços.

Partindo desse entendimento, imagina-se na situação do Brasil, onde a maioria dos empregadores é da classe média, sendo a empregada doméstica para essa classe uma "necessidade e não luxo". Isso poderá resultar, devido à elevação nos custos, numa "contratação informal", impedindo, assim, que recentes mudanças na lei afetem seus contratos de trabalhos (MASCARENHAS, 2013, p. 54). 


\section{CONSIDERAÇÕES FINAIS}

O trabalho doméstico sempre foi uma atividade atribuída às mulheres, que reproduz estigmas e desigualdades, que demandam um grande esforço de superação para a construção de uma identidade profissional. No Brasil, onde tal atividade reproduz os resquícios de uma época colonial, esses serviços já foram interpretados como trabalho escravo.

Observa-se que posterior à abolição da escravidão, algumas normas foram criadas ou redefinidas com o intuito de manter o controle sobre a população escrava. Ou seja, algumas negras dedicadas às atividades domésticas permanecerem nas casas de seus ex-patrões, mantendo assim uma condição diferenciada em relação às demais restantes da população negra.

Destaca-se que a legislação do Século XX permitiu grandes avanços, mas sempre aquém dos direitos das outras categorias de trabalhadores; além disso, foi por meio dos movimentos sindicais que eclodiu a expansão dos direitos trabalhistas das empregadas domésticas.

Enfim, foi percebido que, nos diferentes períodos de governo, o trabalho doméstico tem sido associado à atividade feminina, sendo considerado invisível e desvalorizado. A nova lei da Doméstica tenta intensificar a luta por uma equiparação de direitos frente aos outros trabalhadores, além de buscar a redução da informalidade da atividade doméstica, de forma a garantir para a mesma uma maior autonomia e equidade de gênero no mundo do trabalho.

Essa busca por autonomia feminina por meio da Emenda Constitucional $n^{\circ} .72 / 2013$, apesar de haver ampliado os direitos da empregada doméstica, pode ter efeitos limitadores para o alcance da cidadania ativa feminina, pois não se pode esquecer que os empregadores domésticos são pessoas físicas e que o eventual aumento no orçamento familiar poderá colocar em risco milhares de empregos domésticos, o que gerará um crescimento no mercado informal de trabalho.

Caso haja uma diminuição da disponibilidade no trabalho das empregadas domésticas, decorrente da maior onerosidade do contrato de trabalho, essa situação certamente exigirá uma mudança cultural e nos 
costumes brasileiros, uma vez que tal categoria faz jus aos direitos adquiridos e, com isso, terá que haver um reajuste nas responsabilidades dos membros da família quanto aos cuidados da casa.

Embora essa lei traga novos direitos, que há tempos são almejados, e que de fato os trabalhadores domésticos são merecedores deles, cabe-nos, portanto, refletir como será a repercussão social desses novos direitos, em termos de qualidade de vida no trabalho e relacionamento empregada e patrão. Enfim, são questionamentos que só o tempo, e com estudo aprofundado acerca do assunto, poderá responder. Mas, para isso é importante que se desconstituam conceitos pré-formulados relacionados ao assunto, destacando a importância desses novos direitos para essa categoria profissional e para o seu contexto de vivência.

\section{REFERÊNCIAS}

ALGRANTI, Leila Mezan. Famílias e vida doméstica. In: SOUZA, Laura de Melo e (Org.). História da Vida Privada no Brasil: cotidiano e vida privada na América Portuguesa, São Paulo: Companhia das Letras, 1997 (História da vida privada no Brasil 1).

ANDRADE, D. O. Emenda Constitucional 72/2013 - A especificidade do trabalho doméstico e os limites protetivos da jornada de trabalho, 2014, 73s. Monografia (Bacharel em Direito) - Faculdade de Direito da Universidade de Brasília - Brasília-DF, 2014.

AVELINO, Mario. Cartilha PEC das Domésticas - Direitos e deveres de patrões e empregadas. Disponível em <ocplayer.com. br/1039655-Titulo-cartilha-pec-das-domesticas-direitos-e-deveres-de-patroes-e-empregadas. html> Acessado em 08/07/2016.

O futuro do Emprego Doméstico no Brasil. Instituto Doméstica Legal, 1. ed., Rio de Janeiro-RJ, 2011, 204p.

ÁVILA, Maria Betânia; FERREIRA, Verônica. Trabalho remunerado e trabalho doméstico no cotidiano das mulheres. Realização SOS CORPO Instituto Feminista para Democracia; Instituto Patrícia Galvão, Recife - SOS Corpo-2014, p. 105. 
BENTIVOGLIO, Elaine Cristina Saraiva. A evolução da legislação do trabalho doméstico no Brasil. Revista do Curso de Direito da Faculdade de Humanidades e Direito, v. 11, n. 11, p. 219-232, 2014.

BERNARDINO-COSTA, Joaze. Sindicatos das Trabalhadoras Domésticas no Brasil: Teorias da Descolonização e Saberes Subalternos, 2007, 287s. Tese (Doutorado em Sociologia) - Universidade de Brasília Instituto de Ciências Sociais, Brasília-DF, 2007.

BOAVA, D. L. T. MACEDO, F. M. F. SETTE, R. S. Contribuições do Ensaio Teórico para os Estudos Organizacionais. VII Encontro de Estudos Organizacionais da ANPAD, Curitiba/PR 2012.

BRUSCHINI, Cristina. Trabalho doméstico: inatividade econômica ou trabalho não-remunerado. R. bras. est. Pop., v. 23, n. 2, p. 331-353. 2006.

. Trabalho Feminino trajetória de um tema perspectivas para o futuro. Estudos feministas, v. 2, n. 3, p. 17-32, 1994.

. Revendo estereótipos: o papel dos homens no trabalho doméstico. Estudos Feministas, v. 20 n. 1, p. 259-287, 2012.

CARVALHO, Vânia Carneiro de. Gênero e Artefato. O sistema doméstico na perspectiva da cultura material - São Paulo, 1870-1920, São Paulo: Editora da Universidade de São Paulo/FAPESP, 2008.

CHAGAS, Sylvia Oliveira. Evolução do direito trabalhista do Empregado doméstico de 1916 a 2013 - PEC das domésticas. Cadernos de Graduação Ciências Humanas e Sociais, v. 1, n. 17, p. 63-76, 2013.

CONSTITUIÇÃO 1988. Disponível em <http://www.planalto.gov.br/ccivil 03/constituicao/constituicaocompilado.htm> Acessado em 23/02/2016.

FIGUEIREDO, M. Transição do Brasil Império à República Velha. Revista Iberoamericana de Filosofía, Política y Humanidades, v. 13, n. 26, p. 119145, 2011.

FREYRE, Gilberto. Casa - Grande e Senzala. Formação da família brasileira sob regime da economia patriarcal, 48. ed. rev., São Paulo, Editora Global, 2003.

GOMES, Douglas. Origem do Trabalho Doméstico no Brasil. Disponível em: $<$ http://www.ebah.com.br/content/ABAAAfqd4AK/origem-trabalho-do- 
mestico-no-brasil>. Acesso em 08/07/2016.

JÚNIOR, Marcos. Constituição de 1988 - Sua História e característica. Disponível em < $<$ http://www.estudopratico.com.br/constituicao-de-1988-sua-historia-e-caracteristicas/> Acessado em 23/02/2016.

MARTINS, Sérgio Pinto. Manual do Trabalho Doméstico, 9. ed., São Paulo: Ed. Atlas, 2007.

\section{MASCARENHAS, L. G. S. A nova Legislação do Empregado Doméstico e} a Busca por Igualdade de Direitos, 2013, 59s. Monografia (Bacharel em Direito) - Faculdade de Direito da Universidade de Brasília, Brasília-DF, 2013.

MAZIERO, Luís Guilherme Soares. Direitos Fundamentais e Discriminação de Gênero: a ausência de direitos e proteção ao trabalho doméstico, 2010, 156s. Dissertação (Mestrado em Direito) - Universidade Metodista de Piracicaba, SP, 2010.

MELO, Hildete Pereira de, CASTILHO, Marta. Trabalho reprodutivo no Brasil: quem faz? Rev. econ. contemp. [on-line], v. 13, n. 1, p. 135-158, 2009.

MENEGHETTI, Francis Kanashiro. O que é um Ensaio-Teórico? RAC, v. 15, n. 2, p. 320-332, 2011.

OIT. Trabalho doméstico ocorre na Conferência Internacional do Trabalho de 2010. Disponível em $<$ http://www.ilo.org/wcmsp5/groups/public/--americas/---ro-lima/---ilo-brasilia/documents/publication/wcms_229496.pdf $>$ Acessado em 08/07/2016.

Guia para programas de qualificação para as trabalhadoras domésticas/Organização Internacional do Trabalho (OIT); Programa de Promoção da Igualdade de Gênero e Mais Trabalho Decente para Trabalhadoras e Trabalhadores Domésticos no Brasil.

OIT. Disponível em <http://www.oitbrasil.org.br/sites/default/files/topic/discrimination/doc/trabalho_domestico_40.pdf> Acessado em 08/07/2016.

PEREIRA, Bergman de Paula. O desenvolvimento do trabalho doméstico a partir da legislação do Estado Novo. In: XXI Encontro Estadual de História ANPUH-SP - Anais - Campinas, 2012.

SANCHES, Solange. Trabalho Doméstico: Desafios para o Trabalho Decente. Revista Estudos Feministas, v. 17, n. 3, p. 879-888, 2009. 
SANTOS, Judith Karine Cavalcanti. Quebrando as correntes invisíveis: Uma análise crítica do trabalho doméstico no Brasil, 2010, 85s. Dissertação (Mestrado em Direito, Estado e Constituição) Universidade de Brasília Faculdade de Direito, Brasília-DF, 2010.

SOARES, Evan. Abolição da Escravatura e Princípio da Igualdade no Pensamento Constitucional Brasileiro (Reflexos na Legislação do Trabalho Doméstico). Revista do Ministério Público do Trabalho, n. 39, Ano XX, p. 1-3, 2010.

TEIXEIRA, Kelly Cristine de Oliveira. Trabalho doméstico: um estudo sobre percepções de empregadas domésticas da cidade de Paula Cândido-MG, 2014, 59s. Monografia (graduação em Ciências Sociais) - Universidade Federal de Viçosa-MG, 2014.

ZAMBERLAM, Cristina de Oliveira. Os novos paradigmas da família contemporânea: uma perspectiva interdisciplinar, Rio de Janeiro: Renovar, 2001.

\section{DAdos dos Autores}

\section{Deide Fátima da Silva}

Cursando mestrado no departamento de economia doméstica na Universidade Federal de Viçosa; especialista em Direito do Trabalho e Previdenciário pela ESUV/UNIVIÇOSA e especialista em Direito do Estado pela Universidade Anhanguera/LFG; graduada em Direito pela ESUV/UNIVIÇOSA. deidefs@yahoo.com.br

\section{Maria das Dores Saraiva de Loreto}

Professora e orientadora no Departamento de Economia Doméstica da Universidade Federal de Viçosa/MG mdora@ufv.br

\section{Amélia Carla Sobrinho Bifano}

Professora e co-orientadora no Departamento de Economia Doméstica na Universidade Federal de Viçosa/MG acsbifano@gmail.com

Submetido em: 2-8-2016

Aceito em: 28-11-2016 